\title{
Multidetector Row Computed Tomography(MDCT) Evaluation of Bronchogenic Carcinoma and Histopathological Correlation
}

\author{
Indira Narayanaswamy ${ }^{1}$, Niranjan Jayaram ${ }^{2}$, Suresh Ashwathappa ${ }^{1}$ \\ ${ }^{1}$ Department of Radiodiagnosis, Vydehi Medical College and Research Centre, Whitefield, Bangalore, Karnataka, India \\ ${ }^{2}$ Department of Pathology, Vydehi Medical College and Research Centre, Whitefield, Bangalore, Karnataka, India
}

\section{Email address:}

drindiraniranjan@gmail.com (N. Jayaram),drniranjanjayaram@ hotmail.com (N. Jayaram)

\section{To cite this article:}

Indira Narayanaswamy, Niranjan Jayaram, Suresh Ashwathappa. Multidetector Row Computed Tomography(MDCT) Evaluation of Bronchogenic Carcinoma and Histopathological Correlation. International Journal of Medical Imaging. Vol. 3, No. 4, 2015 , pp. 82-88. doi: 10.11648/j.jimi.20150304.13

\begin{abstract}
Bronchogenic carcinoma is one among the leading causes of death in males in India and globally. Multidetector row Computed Tomography is a non-invasive technique for evaluation of bronchogenic carcinoma. Aims and objections: To document imaging characteristics of various histopathological cell types of bronchogenic carcinoma by MDCT and to correlate with histopathology. A prospective study was done on 60 patients with clinical or radiological suspicion of bronchogenic carcinoma undergoing MDCT. The final diagnosis was established by histopathology. Study duration was for 2 years from January 2013 to December 2014. Results: MDCT is a promising tool in evaluation of bronchogenic carcinoma. Squamous cell carcinoma is the most common histological celltype, closely followed by adenocarcinoma. Hilar mass was the predominant presentation followed by lung mass.
\end{abstract}

Keywords: Multidetector Row Computed Tomography (MDCT), Bronchogenic Carcinoma, Central, Peripheral, Histopathology

\section{Introduction}

Bronchogenic carcinoma is the main leading cause of death in males in India and worldwide accounting for significant mortality. ${ }^{1}$ MDCT is a promising, $3 \mathrm{D}$ imaging tool that allows substantial anatomical volumes covered with isotropic submillimeter spatial resolution. Since the advent of MDCT, a decline in the use of other diagnostic chest procedures like chest fluoroscopy, tomography, mediastinoscopy, arteriography and thoracotomy has occurred $^{2}$.Limited studies have been done regarding the imaging characteristics of various histological cell types of bronchogenic carcinoma in India especially in the south. ${ }^{3}$ The present study was undertaken to document various MDCT features of bronchogenic carcinoma and to correlate with histopathology

\section{Methodology}

Study was done on 60 patients referred for Computed Tomography to Department of Radio-diagnosis, Vydehi
Institute of Medical Sciences and Research Centre, Bangalore with clinical or radiological suspicion of bronchogenic carcinoma. All cases were proven by histopathology. The study duration was 24 months from January 2013 to December 2014. Patients with lung metastasis and benign pathology were excluded.

CT was performed with WIPRO GE 16 Slice CT Scanner with $10 \mathrm{~mm}$ collimation from apices of lung to the domes of diaphragm including the adrenals and whole of liver. 60-70 $\mathrm{ml}$ of non-ionic contrast was injected intravenously.

The following primary CT features like mass, location, attenuation, enhancement, calcifications, cavitations, satellite lesions were looked for. Secondary features like lymph nodes, mediastinal or chest wall invasion, pleural effusion, collapse, consolidation and metastases were evaluated.

Statistical method: Results on continuous measurements were performed on mean SD (Min - Max) and results on categorical measurements were presented in number (\%). Significance is assessed at 5\% level of significance. Chi square/ Fisher Exact test has been used to find the significance of study parameters on categorical scale between 
two or more groups. The statistical software namely SAS 9.2, SPSS 15.0, Stata 10.1, MedCalc (.0.1, Systat 12.0 and R environment ver.2.11.1 were used for the analysis of the data and Microsoft word and Excel have been used to generate graphs, tables etc.

\section{Results}

Highest number of patients were found in the age group of 51-60 years (22 patients) which constituted $36.7 \%$ of patients followed by the age group of 61-70 (20 patients) which constituted $33.33 \%$. Mean age was 57.10 +/- 10.47 years (Table1). Out of 60 patients 53 patients were males $(88.3 \%)$ and 7 were females $(11.7 \%)$ (Figure 1$)$.

Out of 60 patients, 39 were smokers $(65.0 \%), 10$ were non-smokers (16.7\%) and 11 were ex-smokers (18.3\%).

Majority of patients $(37,61.7 \%)$ presented with peripheral mass lesions. In $23(38.3 \%)$ patients presented in central locations (Table 2)

Out of 60 cases, squamous cell carcinoma accounted for maximum number of cases accounting for 28 cases (46.7\%) followed by adenocarcinoma 20 cases $(33.3 \%)$ and least was large cell carcinoma found in 2 cases (3.33\%) (Table 3 )

Squamous cell carcinoma was the commonest tumour and was seen both in central and peripheral locations. Adenocarcinoma was mostly seen in peripheral locations. Small cell carcinoma was exclusively seen as central tumour. Large cell and undifferentiated were seen in both central and peripheral locations (Figure 2).

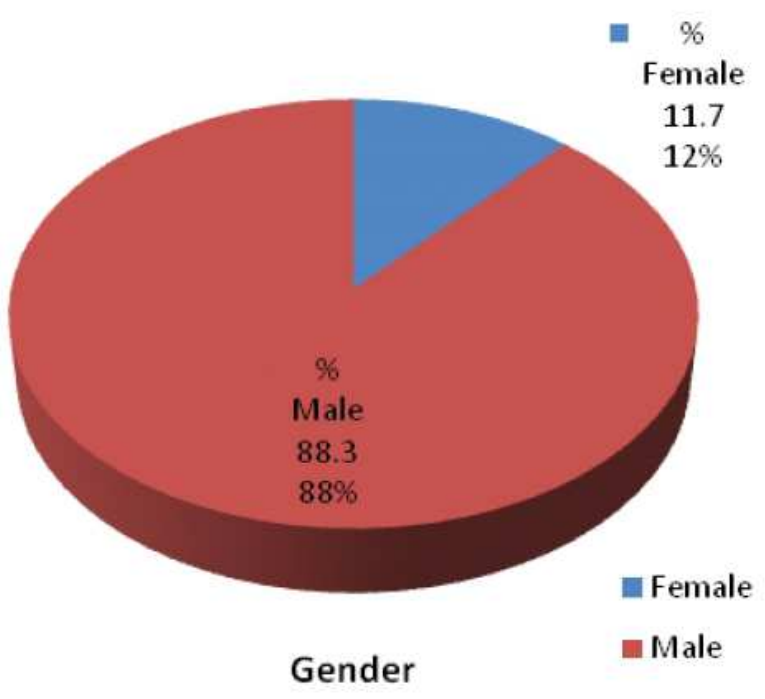

Figure 1. Gender distribution of Patients studied.

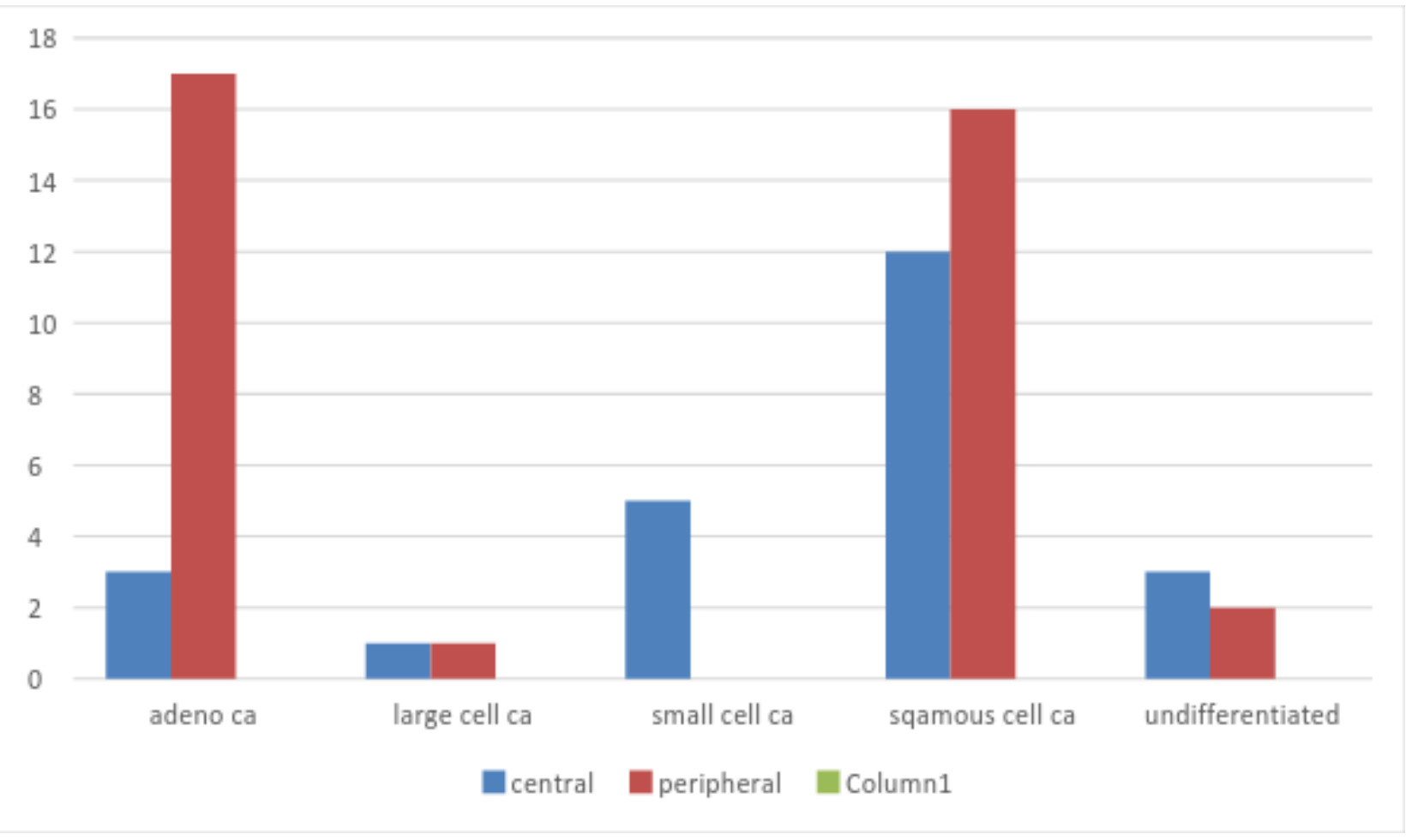

$\mathrm{P}<0.001 * *$, Significant, Fisher Exact test

Figure 2. Showing association of histological cell types with central/peripheral locations.

Out of 60 patients 28 cases $(46.7 \%)$ were squamous cell carcinoma, presenting centrally in 12 case $(42 \%)$ and peripherally in 16 cases $(57 \%)$. Out of 60 patients , 20 cases ( $33.3 \%$ ) were adenocarcinoma, presenting centrally in 3 cases $(15 \%)$ and peripherally in 17 cases $(85 \%)$.

5 cases $(8.33 \%)$ were small cell carcinoma presenting only in central locations. 2 cases $(3.33 \%)$ were large cell carcinoma presenting both centrally $(50 \%)$ and peripherally $(50 \%) .3$ cases $(5 \%)$ were undifferentiated presenting in both central (60\%) and peripheral locations (40\%).

Hilar mass was the most common presentation (40\%) seen mostly by squamous cell carcinoma, followed by small cell 
carcinoma (which is central tumour), adenocarcinoma and undifferentiated carcinoma in that order. Lung mass was the next common feature found in adenocarcinomas. Squamous cell carcinomas also presented as Pancoast or chest wall masses. Cavitary lesions were seen both in adenocarcinoma and squamous cell carcinoma. SPN was a feature of adenocarcinoma. (Table 4)

Table 1. Age distribution of patients studied.

\begin{tabular}{lll}
\hline Age in years & No.of patients & $\%$ \\
\hline $21-30$ & 2 & 3.3 \\
$31-40$ & 1 & 1.7 \\
$41-50$ & 12 & 20.0 \\
$51-60$ & 22 & 36.7 \\
$61-70$ & 20 & 33.3 \\
$71-80$ & 3 & 5.0 \\
Total & 60 & 100.0 \\
\hline
\end{tabular}

Table 4. Distribution of histological cell types according to the radiological findings.

\begin{tabular}{llllll}
\hline & Hilar mass & Lung mass & Spiculated Lobulated & Spn & Cavitory \\
\hline SQ & 12 & 2 & & 1 & 2 \\
Adeno & 3 & 8 & 4 & 4 & \\
Large & 1 & 1 & & & \\
Small & 5 & & & & \\
Undiff & 3 & 2 & 4 & 1 & 6 \\
Total & 24 & 11 & 4 & & 12 \\
\hline
\end{tabular}

\section{Discussion}

In the present study the mean age of the patients was 57 which was close to Prasad ${ }^{4}$ et al lucknow India and A dey Kolkatta. Majority of lung cancer fell between the age group 40 to 70 years.

Gender distribution was $M: F-7.5: 1$, this is in close relation with Santos - martinez ${ }^{6}$ and Jagdish ${ }^{7}$ gender distribution of patients studied. Cough was the most common symptom followed by chest pain, weight loss and pleural effusion. One case presented with CNS features and retrospectively diagnosed due to bronchogenic carcinoma.

Squamous was seen most commonly in smokers. Adenocarcinoma was most common in non-smokers and females.

Squamous formed the major histologic cell type accounting for $46 \%$ followed by adenocarcinoma accounting for $33 \%$, small cell carcinoma was found in $11.6 \%$ and large cell carcinoma in $8.3 \%$. These findings were similar to various studies done by Jindal ${ }^{8}$ and Gupta. ${ }^{9}$ The ratio of squamous cell carcinoma to adenocarcinoma was 1.39:1. The rise in adenocarcinoma is significant in USA but not in India, where squamous cell carcinoma still dominates but the ratio is declining from $1.7: 1$ to $1.39 .^{9}{ }^{10}$ In the last 30 years, there has been a relative increase in the number of adenocarcinoma, bringing that ratio to $14: 1 .^{10.11}$ This may be due to the fact that more and more adenocarcinomas are diagnosed by immunohistochemistry.

Squamous cell carcinoma was seen both in central and peripheral locations. It presented as hilar mass in central locations and Pancoast and chest wall invasive lesions in peripheral locations. Adenocarcinoma was most commonly
Table 2. Central/Peripheral locations of patients studied.

\begin{tabular}{lll}
\hline Central/ peripheral & Number of patients & \% \\
\hline Central & 23 & $38.3 \%$ \\
Peripheral & 37 & $61.7 \%$ \\
Total & 60 & 100.0 \\
\hline
\end{tabular}

Statistically significant $(\mathrm{P}<0.001 * *)$

Table 3. Histology of patients studied.

\begin{tabular}{lll}
\hline Histology & Number of patients & $\mathbf{\%}$ \\
\hline Adenocarcinoma & 20 & $33.3 \%$ \\
Large cell carcinoma & 2 & $3.33 \%$ \\
Small cell carcinoma & 5 & $8.3 \%$ \\
Squamous cell carcinoma & 28 & $46.7 \%$ \\
Undifferentiated & 5 & $8.33 \%$ \\
Total & 60 & 100.0 \\
\hline
\end{tabular}

located in the periphery, with lung mass as a presenting radiological feature. Large cell and undifferentiated were seen in both central and peripheral locations. Small cell carcinoma was seen exclusively in central location.

Hilar mass was the most common presentation, though studies by Loris $^{12}$ et al showed that lung mass was the commonest presentation.

\section{Squamous cell carcinoma}
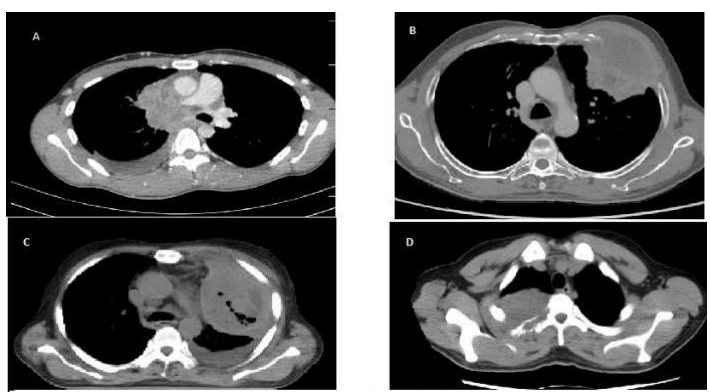

Image 1a. Squamous cell carcinoma presenting as hilar mass, chest wall mass, cavitary lesion and Pancoast tumor.

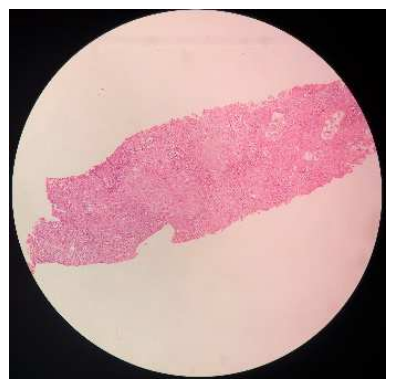

Image 1b. Squamous cell carcinoma 10x $H \& E$. 
Among 28 cases of squamous cell carcinomas, equal numbers were found as hilar and peripheral masses. Tumours usually ranged in size from $1-10 \mathrm{cms}$. The large size of tumour at the time of presentation is due to slow growth. ${ }^{11}$ Centrally, the masses were typically found in the central bronchi, resulting in post obstructive pneumonia and atelectasis in up to $80 \% .^{12}$ Mucoid impaction, bronchiectasis and hyperinflation are additional findings of a central obstructing neoplasm. Extension into the chest wall or mediastinum with bone destruction, superior vena cava syndrome, phrenic or recurrent laryngeal nerve paralysis has been reported. ${ }^{13}$

Peripheral masses were seen as Pancoast/superior sulcus tumours or peripheral chest wall masses either causing rib destruction or chest wall invasion. Squamous cell carcinoma

is the most common cell type to present as Pancoast or Superior sulcus tumour ${ }^{13}$ and this was seen in 5 cases $(17 \%)$ and as peripheral masses eroding the rib or chest wall invasion in 7 cases $(25 \%)$. They are usually slow growing with late metastasis predominantly to the liver, adrenal glands, kidneys and bones. ${ }^{13}$

Squamous cell carcinoma cavitates in 10 to $20 \%$ of cases particularly, the large peripheral lesions. ${ }^{13}$

$2(7.14 \%)$ cases were seen as thick walled cavitary lesions. Cavity walls were thick and irregular ranging 0.5 to $1.5 \mathrm{~cm}$. Rarely, extensive necrosis within the mass can be seen as thin-walled cavity. ${ }^{14}$

\section{Adenocarcinoma}
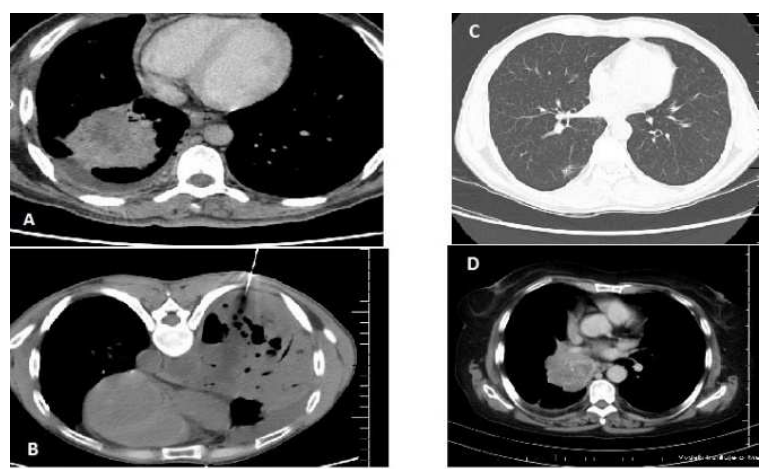

Image 2a. Adenocarcinoma presenting as lung mass, spiculated mass, cavitary lesion and hilar mass.

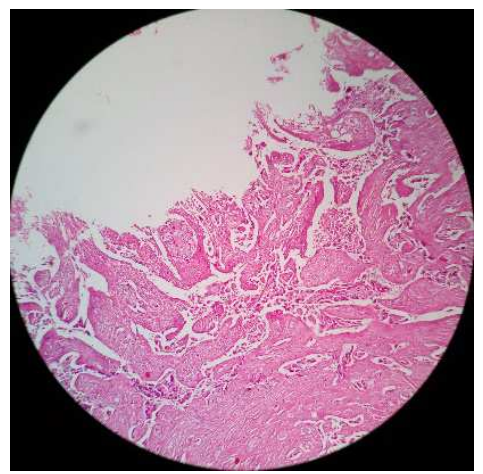

Image 2b. Adenocarcinoma 40x H\&E.

Adenocarcinoma accounted for $33 \%$ of all malignant tumours with only $15 \%$ were seen as central hilar masses. Only one case showed frank intraluminal extension. Recent studies by Shetty et $\mathrm{al}^{3}$ have shown that adenocarcinoma predominantly presented as central masses. However we saw adenocarcinomas predominantly located in the periphery as consolidative process, lung masses around the segmental bronchi, spiculated or lobulated peripheral masses, SPN, cavitary lesions and. Lung masses around the segmental bronchi accounted for $47 \%$ and was the most common presentation. Air Bronchogram sign was seen in $40 \%$ of cases. Small spiculated masses were seen in $15 \%$ of cases and lobulated masses were seen in $5 \%$. One case $(5 \%)$ presented as SPN. 2 cases $(10 \%)$ were seen as cavitatory lesions and 2 cases $(10 \%)$ cases presented as Bronchoalveolar
carcinoma.(BAC)

The borders of the tumour were rounded, lobulated or poorly defined. Lobulation reflects the histologic heterogeneity of lung cancer due to the differential growth rates in different areas within the tumour. Ill-defined bonders may relate to invasion of the adjacent lung, fibrosis, or interstitial oedema. ${ }^{21}$ The typical radiologic manifestation of adenocancinoma is a solitary pulmonary nodule or mass that may have well-marginated, lobulated, irregular or poorly defined borders. ${ }^{22}$

The most common radiologic manifestation of the bronchioloalveolar subtype of adenocarcinoma is that of a well-circumscribed peripheral solitary pulmonary nodule or mass. ${ }^{23}$ Cavitation, an infrequent finding in adenocarcinomas, may be seen in bronchioloalveolar carcinoma. The lepidic 
pattern of tumor growth may result in lesions of heterogeneous radiologic opacity, with air bronchograms and poorly marginated borders mimicking pneumonia. ${ }^{24}$ Less commonly, patterns of multiple nodules or extensive consolidation involving one on more lobes may be seen. ${ }^{25} 26$ Patients with extensive consolidation of multifocal disease have a poor prognosis. High-resolution CT may demonstrate air attenuation and pseudocavitation within the nodules corresponding to small bronchi and cystic spaces ${ }^{26}$

\section{Small cell carcinoma}

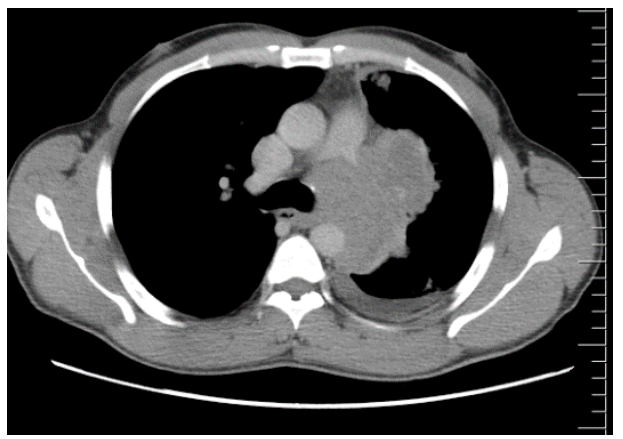

Image 3a. Small cell carcinoma presenting as hilar mass.

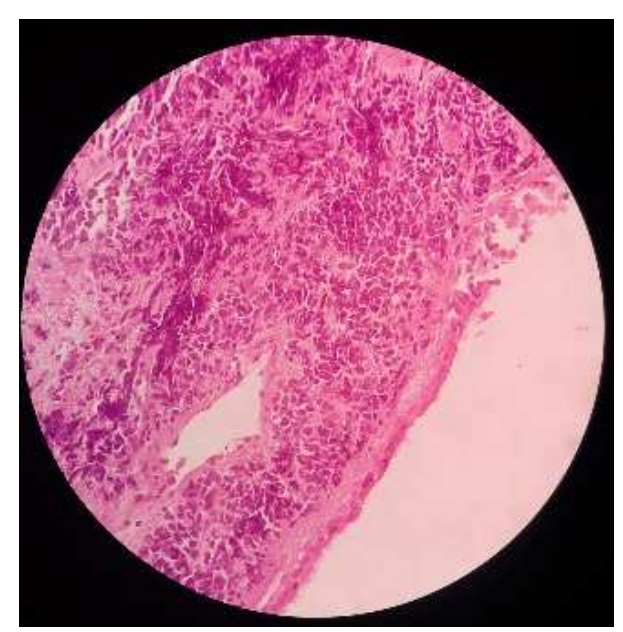

Image 3b. Small cell carcinoma. 40xH\&E.

5 cases $(8.33 \%$ of 60 lung cancers $)$ were small cell carcinomas. They probably arise from neuroendocrine cells and contain neurosecretory granules and may produce peptide hormones. ${ }^{15,16}$ The tumours were centrally located and mediastinal extension was seen with encasement of mediastinal structures and tracheobronchial compression in

$60 \%$ of cases. ${ }^{17,18}$ The less commonly described peripheral small cell carcinoma is often associated with hilar adenopathy and atelectasis secondary to main stem bronchus compression. $^{19}$

\section{Large cell carcinoma}

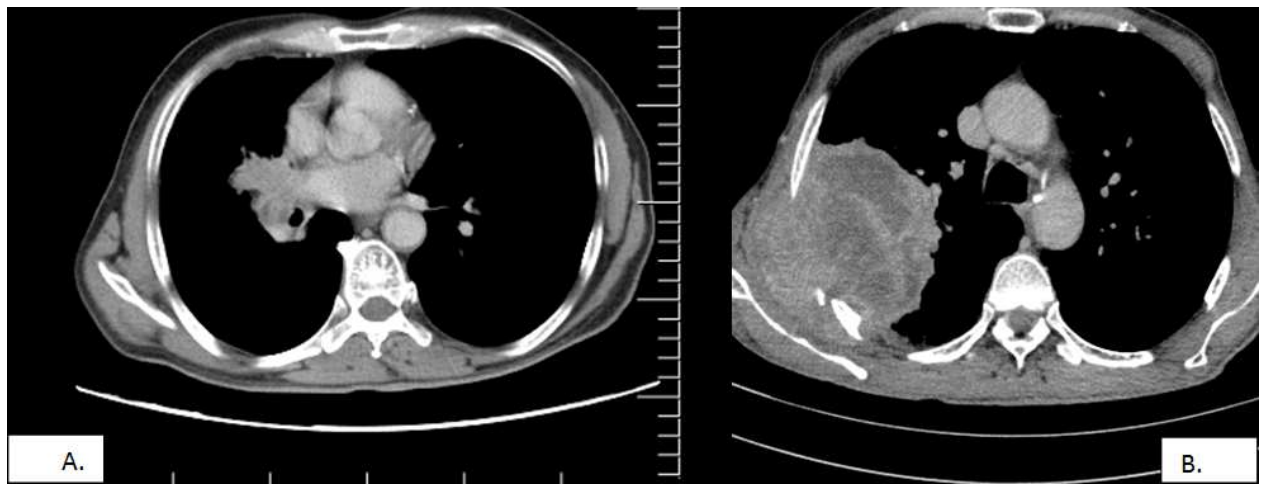

Image 4. Large cell carcinoma presenting as hilar and peripheral lung masses.

Large cell carcinoma represents less than $5 \%$ of all bronchogenic carcinomas and can present in both central and peripheral locations. Here large cell carcinomas were seen as hilar and lung masses. 
Undifferentiated carcinoma
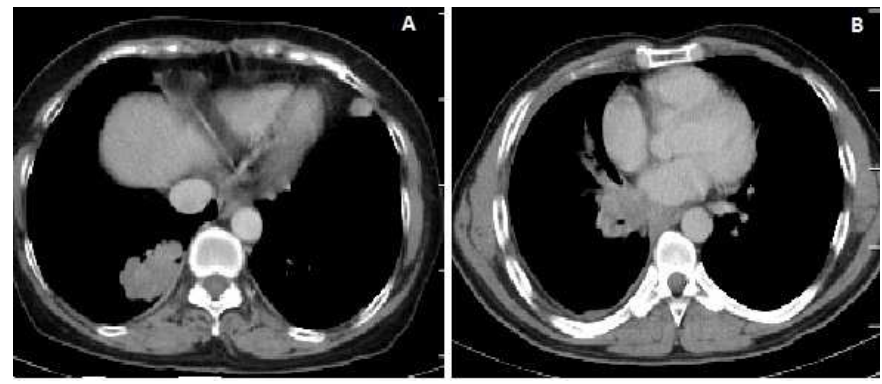

Image 5. Undifferentiated carcinoma presenting as peripheral and hilar masses.

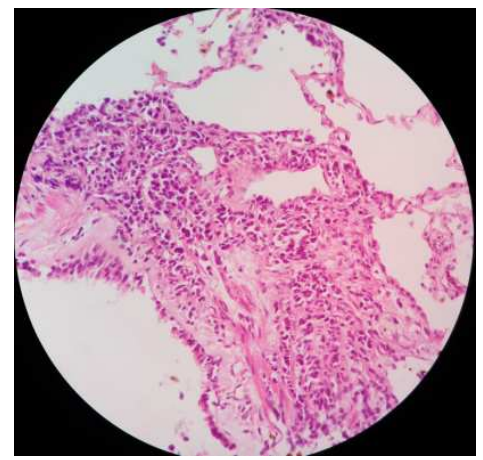

Image 6. Undifferentiated carcinoma $40 x H \& E$.

Undifferentiated carcinomas are usually bulky tumours typically greater than $3 \mathrm{~cm}$ in diameter. Involvement of large bronchi is seen in approximately $50 \%$ of central lesions. The typical radiologic appearance of these neoplasms is that of a large peripheral lung mass and have large areas of necrosis.

Other features:

Mediastinal lymph nodes were seen invariably in squamous cell, small cell, large cell, undifferentiated and adenocarcinomas in that order. Central masses had more association with lymph nodes $(85 \%)$. Pleural effusion was predominantly seen in adenocarcinoma, followed by squamous cell carcinoma. Metastases to liver, adrenal, bone and brain were seen predominantly in adenocarcinoma.

\section{Conclusion}

MDCT with precise anatomic details is the imaging modality of choice in assessment of various histopathological celltypes of bronchogenic carcinoma. Squamous cell carcinoma is the commonest histologic celltype, presenting as hilar mass whereas adenocarcinoma is seen predominantly in peripheral location presenting as lung mass.

\section{References}

[1] Ishikawa H, Koizumi N, Morita T, Tani Y, Tsuchida M, Umezu H, Naito M, Sasai K. Ultrasmall pulmonary opacities on multidetector-row high resolution computed tomography: a prospective radiologic-pathologic examination $\mathrm{J}$ Comput Assist Tomogr. 2005 Sep-Oct; 29(5):621-5

[2] Christoph Schimmer etal, Staging of Non Small cell cancer;
Clinical value of PET and Mediastino scopy.ICVTS 5,2006, vol-20,issue $6,418-430$

[3] Shetty CM, Lakhar BN, Gangadhar VSS et al: changing pattern of bronchogenic carcinoma: a statistical variation or a reality? Ind J Radiol Imag 2005 15:1:233-238

[4] Prasad R, James P, Kesarwani V, Gupta R, Pant MC, Chaturvedi A, et al. Clinicopathological study of bronchogenic carcinoma. R4espirology 2004; 9:557-60.

[5] Dey A, Biswas D, Saha SK, Kundu S, Sengupta A. Comparison study of clinicoradiological profile of primary lung cancer cases: An eastern India experience. Indian J Cancer 2012; 49:89-95.

[6] Santos-Martinez MJ, Curull V, Blanco ML, Macia F, Mojal S, Vila $J$, et al. Lung cancer at a university hospital: Epidemiological and histological characteristics of a recent and historic series. Arch Bronchoneumol 2005; 41:301-12.

[7] Rawat J, Sindhwani G, Gaur D, Dua R, Saini S. Clinicopathological profile of lung cancer in Uttarkhand. Lung India 2009; 26:74-6.

[8] Jindal SK, Behera D. Clinical spectrum of primary lung cancer: Review of Chandigarh experience of 10 years. Lung India 1990; 8:94-8.

[9] Gupta, RC, Purohit SD, Sharma MP, Bhardaj S. Primary bronchogenic ca: clinical profile of 279 cases from middle east Rajasthan. Indian J chest dis Allied Sci; 1998:109-16.

[10] Jackson CL, Huber JF. Correlated applied anatomy of the bronchial tree and lungs with system of nomenclature. Dis Chest 1943; 9:319.

[11] Pump KK. The morphology of the finer branches of the bronchial tree of the human lung. Dis Chest 
[12] Yosri M. Aki, Raef H et al, Clinico - Pathological profile of bronchogenic carcinoma cases presented to chest department, Cairo University. EJCT. SEP 2013.

[13] Sider L. Radiographic manifestations of primary bronchogenic carcinoma. Radiol Clin North Am 1990; 28:583 597.

[14] Byrd RB, Carr DT, Miller WE, et al. Radiographic abnormalities in carcinoma of the lung as related to histological cell. Thorax 1969; 24:573 575.

[15] Matthews MJ. Morphology of lung cancer. Semin Oncol 1974; 1:175 182 .

[16] Haque AK. Pathology of carcinoma of lung: an update on current concepts. J Thorac Imaging 1991; 7:9 20.

[17] Pearlberg JL, Sandler MA, Lewis Jr JW, et al. Small-cell bronchogenic carcinoma: CT evaluation. AJR Am J Roentgenol 1988; 150:265 268.

[18] Whitley NO, Fuks JZ, McCrea ES, et al. Computed tomography of the chest in small cell lung cancer: potential new prognostic signs. AJR Am J Roentgenol 1984; 141:885 892.

[19] Filderman AE, Shaw C, Matthay RA. Lung cancer. Part I:
Etiology, pathology, natural history, manifestations, and diagnostic techniques. Invest Radiol 1986; 21:80 90. 23

[20] Kuriyama K, Tateishi R, Doi 0, et al. Prevalence of air bronchograms in small peripheral carcinomas of the lung on thin-section CT: comparison with benign tumors. AJR 1991; 156:921-924.

[21] Epstein DM, Gefter WB, Miller WT. Lobar bronchioloalveolar cell carcinoma. AJR 1982; 139:463468.

[22] Hill CA. Bronchioloalveolar carcinoma: a review.Radiology 1984; 150: 15-20.

[23] Fraser RG, Pare JAP, Pare PD, Fraser Rs, Genereux GP. Neoplastic disease of the lung. In: Fraser RG, Pare JAP, Pare PD, Fraser RS, Genereux GP, eds. Diagnosis of the chest. $3^{\text {rd }}$ ed. Philadelphilpia, Pa: saundes, 1989; 1327-1699.

[24] Romney B, Austin JHM,. Plain film evaluation of carcinoma of the lung. Semin Roentgenol 1990; 25:45-63.

[25] Adler B, Parley, Miller R, Muller NL. High resolution CT of bronchioalveolar carcinoma. AJR 1992; 159:275-277.

[26] Martini N. Operable lung cancer. CA Cancer J Clin 1993; 43:201-2 14 . 